\begin{tabular}{|l|l|l||}
\hline \multicolumn{2}{|c|}{ PublisherInfo } \\
\hline \hline PublisherName & $:$ & BioMed Central \\
\hline \hline PublisherLocation & $:$ & London \\
\hline \hline PublisherImprintName & $:$ & BioMed Central \\
\hline \hline
\end{tabular}

\title{
Suck provides a better index than blow
}

\begin{tabular}{|l|l|l||}
\hline \multicolumn{2}{|c|}{ ArticleInfo } \\
\hline \hline ArticleID & $:$ & 1648 \\
\hline \hline ArticleDOI & $:$ & $10.1186 /$ rr-2001-68581 \\
\hline \hline ArticleCitationID & $:$ & 68581 \\
\hline \hline ArticleSequenceNumber & $:$ & 59 \\
\hline \hline ArticleCategory & $:$ & Paper Report \\
\hline \hline ArticleFirstPage & $:$ & 1 \\
\hline \hline ArticleLastPage & $:$ & 4 \\
\hline \hline & & RegistrationDate $: 2001-9-19$ \\
& $:$ & Received \\
\hline ArticleHistory & Accepted 2000-8-18 \\
& $:$ 2001-9-19 \\
\hline \hline ArticleCopyright & $:$ & Biomed Central Ltd2001 \\
\hline \hline ArticleGrants & $:$ & \\
\hline \hline ArticleContext & $:$ & 129312211 \\
\hline \hline
\end{tabular}


Richard Robbins, ,ff1

Corresponding Affiliation: Aff1

Aff1 University of Arizona, USA

Keywords

Chronic obstructive pulmonary disease, COPD, dyspnea, pulmonary function testing, inspiratory force

\section{Introduction}

Expiratory airway collapse is a characteristic feature of patients with (COPD). The authors hypothesized that this collapse would mask the effects of bronchodilators during forced expiration but not during forced inspiration, and that, accordingly, the improvement in forced inspiration and not that in forced expiration with bronchodilator therapy would be related to changes in the perception of dyspnea.

\section{Comments}

The lack of correlation between forced expiratory volume in one second $\left(\mathrm{FEV}_{1}\right)$ and dyspnea is well known and sometimes perplexing. It has been noticed that some asthmatic patients are good perceivers of changes in their pulmonary function tests while others are not; this observation has been extended to include patients with chronic obstructive pulmonary disease (COPD). A number of parameters have been examined to explain this difference, including arterial blood gases (particularly $\mathrm{pCO}_{2}$ ); however, most have given only a rough correlation with the perception of changes in pulmonary function or dyspnea. In this article the authors demonstrate that changes in inspiratory parameters, such as forced inspiratory volume in one second (FIV 1 ) and inspiratory capacity (IC), correlate with changes in dyspnea to a greater extent than expiratory pulmonary function tests. With modern spirometric devices one can often easily obtain inspiratory parameters; examining these values may be valuable and provide useful information in explaining the variable dyspnea perceived by patients with COPD.

\section{Methods}


The authors conducted lung function measurements, including measurements of forced inspiration and expiration before and $30 \mathrm{~min}$ after inhalation of $400 \mu \mathrm{g}$ salbutamol, in 61 patients with COPD and performed expiratory and inspiratory spirometry. The change in dyspnea from baseline was assessed with a standard visual analogue scale.

\section{Results}

Salbutamol induced an improvement of $0.16 \pm 0.02 \mathrm{~L}$ (mean $\pm \mathrm{SD}$ ) in FEV $1,0.36 \pm 0.04 \mathrm{~L}_{\text {in }} \mathrm{FIV}_{1}$, $0.30 \pm 0.04 \mathrm{~L}$ in $\mathrm{IC}$, and $-0.34 \pm 0.07 \mathrm{~L}$ in intrathoracic gas volume. Factor analysis demonstrated that the reduction in dyspnea at rest was primarily associated with changes in parameters describing forced inspiration and not with those of forced expiration or lung hyperinflation, including IC.

\section{Discussion}

The authors state that their data demonstrate that, in patients with COPD, the reduction in dyspnea after inhalation of a $\beta 2$-adrenoreceptor agonist is closely correlated with the change in parameters of forced inspiration, and particularly FIV 1 , but not with changes in parameters of forced expiration or lung hyperinflation.

\section{Additional information}

Additional references:

Wolkove N, Dajczman E, Colacone A, Kreisman H: The relationship between pulmonary function and dyspnea in obstructive lung disease.

Chest 1989, 96:1247-51

Noseda A, Schmerber J, Prigogine T, Yernault JC: How do patients with either asthma or COPD perceive acute bronchodilation?

Eur Respir J 1993, 6:636-44

Similar study to that on which I have reported. Studied asthma and COPD subjects and suggests that dyspnea correlated best with specific inspiratory resistance. Concept is similar overall to the one discussed here. 


\section{References}

1. Taube C, Lehnigk B, Paasch K, Kirsten DK, Jorres RA, Magnussen H: Factor analysis of changes in dyspnea and lung function parameters after bronchodilation in chronic obstructive pulmonary disease. Am J Respir Crit Care Med. 2000, 162: 216-220.

This PDF file was created after publication. 